\title{
CORRECTION
}

\section{HYPOTHESIS TESTING ON THE CORRELATION COEFFICIENT}

L. Greco, S. Naddeo

J. It. Statist. Soc. (1995), vol. 4, n. 2, pp. 271-277

In Table 1 symbol $\varrho$ was inadvertently changed in $\alpha$. The right table is

Table 1

The likelihood-ratio test significance levels

\begin{tabular}{ccccc}
\hline$n$ & $\varrho$ & $\alpha=0,10$ & $\alpha=0,05$ & $\alpha=0,01$ \\
\hline 5 & 0,00 & 0,1009 & 0,0499 & 0,0095 \\
& 0,10 & 0,1009 & 0,0499 & 0,0095 \\
& 0,30 & 0,1012 & 0,0502 & 0,0096 \\
& 0,50 & 0,1016 & 0,0506 & 0,0098 \\
& 0,70 & 0,1019 & 0,0510 & 0,0100 \\
& 0,90 & 0,1012 & 0,0507 & 0,0101 \\
& 0,95 & 0,1006 & 0,0503 & 0,0100 \\
& 0,99 & 0,0999 & 0,0498 & 0,0098 \\
& & & & \\
10 & 0,00 & 0,1003 & 0,0501 & 0,0100 \\
& 0,10 & 0,1003 & 0,0501 & 0,0100 \\
& 0,30 & 0,1003 & 0,0501 & 0,0100 \\
& 0,50 & 0,1004 & 0,0502 & 0,0100 \\
0,70 & 0,1004 & 0,0502 & 0,0101 \\
& 0,90 & 0,1002 & 0,0501 & 0,0100 \\
0,95 & 0,1000 & 0,0500 & 0,0100 \\
0,99 & 0,0999 & 0,0499 & 0,0100 \\
\hline
\end{tabular}

Address for correspondence: L. Greco, Dipartimento di Metodi Quantitativi, Università di Siena, P.zza S. Francesco, I - 53100 Siena, Italy. 